\title{
Indicadores ambientais aplicados à gestão municipal: uma aplicação do modelo Geo cidades em Sumé/PB
}

Considerando que os indicadores de sustentabilidade são ferramentas eficientes na tomada de decisões e que os problemas decorrentes do processo de urbanização, bem como os problemas ambientais podem gerar sérios danos sociais e econômicos a uma sociedade, este estudo teve como objetivo geral analisar formas de contribuição para melhorias na gestão do município de Sumé-PB a partir da utilização de indicadores ambientais. A fim de alcançar aos objetivos propostos, o estudo realizou a aplicação do modelo Força Motriz - Pressão - Estado - Impacto - Resposta (FPEIR) ao município em análise, a partir da metodologia Geo Cidades. Quanto aos procedimentos metodológicos trata-se de pesquisa descritiva e exploratória, adotando-se uma abordagem qualitativa, foram identificados os problemas ambientais do município e posteriormente a seleção de vinte e dois indicadores ambientais, permitindo a produção do modelo FPEIR que demonstrou as relações de causa e efeito entre os indicadores de cada dimensão. Os resultados encontrados mostram a necessidade da elaboração e/ou reformulação de políticas públicas voltadas para gestão de recursos hídricos, resíduos sólidos e política urbana.

Palavras-chave: Indicadores de Sustentabilidade; Indicadores Ambientais; Urbanização.

\section{Environmental indicators applied to municipal management: an application of the Geo cities model in Sumé/PB}

\begin{abstract}
Considering that sustainability indicators are efficient tools in decision-making and that the problems arising from the urbanization process, as well as environmental problems can generate serious social and economic damage to a society, this study aimed to analyze ways of contributing to improvements in the management of the municipality of Sumé-PB based on the use of environmental indicators. In order to achieve the proposed objectives, the study carried out the application of the Driving Force - Pressure - State - Impact - Response (FPEIR) model to the municipality under analysis, using the GeoCidades methodology. As for the methodological procedures, this is a descriptive and exploratory research, adopting a qualitative approach, the environmental problems of the municipality were identified and later the selection of twenty-two environmental indicators, allowing the production of the FPEIR model that demonstrated the cause relationships and effect between the indicators of each dimension. The results found show the need for the elaboration and/or reformulation of public policies aimed at the management of water resources, solid waste and urban policy.
\end{abstract}

Keywords: Sustainability Indicators; Environmental Indicators; Urbanization.

Topic: Uso Sustentável da Biodiversidade

Reviewed anonymously in the process of blind peer
Received: 03/04/2021

Approved: 26/04/2021
Tamires Campos de Macêdo de Sousa (iD

Universidade Federal de Campina Grande, Brasil

http://lattes.cnpq.br/1337038667973625

http://orcid.org/0000-0003-2312-1908

tamirescms@hotmail.com

Kettrin Farias Bem Maracajá (iD)

Universidade Federal de Campina Grande, Brasil

http://lattes.cnpq.br/5398977630029480

http://orcid.org/0000-0002-8189-109X

kettrinfarias@hotmail.com

Gesinaldo Ataíde Cândido (ib)

Universidade Federal de Campina Grande, Brasil

http://lattes.cnpq.br/2771934125977891

http://orcid.org/0000-0002-3112-0254

gacandido01@gmail.com
Referencing this:

SOUSA, T. C. M.; MARACAJÁ, K. F. B.; CÂNDIDO, G. A.. Título: Indicadores ambientais aplicados à gestão municipal: uma aplicação do modelo Geo cidades em Sumé/PB. Revista Ibero Americana de Ciências Ambientais, v.12, n.4, p.194-206, 2021. DOI:

http://doi.org/10.6008/CBPC2179-6858.2021.004.0017 


\section{INTRODUÇÃO}

Com o objetivo de contribuir com a melhoria das ações e práticas do Estado em prol da sociedade, as políticas públicas constituem-se em instrumentos relevantes neste processo, tendo como objetivo promover o bem-estar à sociedade, bem como atender à suas demandas, através de práticas e ações. Neste sentido, nas organizações públicas, é possível observar a incorporação das políticas públicas, nos processos de formulação, implementação, execução, avaliação e monitoramento.

Diante do cenário de crise econômica, política e sanitária enfrentada pelo país, a gestão eficiente de recursos públicos torna-se tarefa ainda mais difícil, sobretudo, pelo impacto causado diretamente na arrecadação das receitas próprias e de transferências. No contexto da gestão municipal, não é diferente, os municípios enfrentam dificuldades na arrecadação dos tributos, limitando a administração a ser eficiente com os repasses da União e Estados.

No que diz respeito a instrumentos de monitoramento e avaliação, segundo Van Bellen (2002), os indicadores, de forma geral, são utilizados para simplificar informações sobre fenômenos complexos e para tornar a comunicação acerca destes fenômenos mais compreensível e quantificável. Para Philippi Junior et al. (2012), em se tratando de informações que auxiliam os gestores na tomada de decisão, os indicadores ambientais têm como objetivo expressar a informação técnica-científica sobre o meio-ambiente e, aplicados ao contexto municipal enfocado, representam de forma integrada um conjunto de dados, informações e conhecimentos acerca de determinado fenômeno urbano-ambiental, capaz de expressar e comunicar, de maneira simples e objetiva, as características essenciais e o significado desse fenômeno aos tomadores de decisão e à sociedade em geral.

Um dos modelos que se sobressai para sistematizar os problemas ambientais é o Sistema de Indicadores de Sustentabilidade Força Motriz - Pressão - Estado - Impacto - Resposta (FPEIR ou DPSIR, Driver - Pressure - State - Impact - Response) (FELINTO et al., 2019). O modelo FPEIR, foi desenvolvido a partir da estrutura PEIR - Pressão, Estado, Impacto e Resposta, elaborada pelo Programa das Nações Unidas para o Meio Ambiente - PNUMA.

Outro ponto que deve ser considerado sobre os problemas ambientais é o processo de urbanização. Para Cardoso et al. (2011), pensar a urbanização atualmente é pensar nos espaços e o que está sendo feito com esses espaços, valendo ressaltar que os espaços são mutáveis e uma condição importante para a mudança dos espaços é a interferência do homem nesse processo, tanto como agente transformador como também de agente transformado do processo de urbanização.

Na tentativa de promover um melhor entendimento sobre as dinâmicas das cidades e o meio ambiente, o projeto Geo Cidades procura fornecer aos governos nacionais, cientistas, gestores e ao público em geral informações confiáveis, atuais e de fácil entendimento sobre suas cidades para auxiliar na promoção da gestão urbana e elaboração de políticas públicas (CRESPO et al., 2002).

Na região semiárida do Brasil, o crescimento econômico está baseado, primordialmente, na exploração dos recursos naturais. Isto não constitui um problema em si, exceto quando o uso dos recursos 
se faz sob um princípio de maximização dos benefícios em curto prazo, sem objetivos de sustentabilidade em longo prazo (SILVA et al., 2018). O município de Sumé, localizado no Cariri Ocidental Paraibano, tem população estimada em 19.966 pessoas. Situado na região do Alto Rio Paraíba, inserida no Polígono das Secas, a área possui um clima do tipo semiárido quente, com chuvas de verão. Pressões de caráter econômico e socioambientais afetam o município, como por exemplo, a dificuldade de acesso à recursos hídricos e a falta de tratamento do esgotamento sanitário.

Ante o exposto, considerando que os indicadores ambientais são instrumentos que fornecem informações relevantes aos gestores públicos no processo de tomada de decisões e, que podem ser úteis para a resolução dos problemas ambientais supracitados, o objetivo do artigo é analisar formas de contribuição para melhorias na gestão do município de Sumé - PB a partir da utilização de indicadores ambientais.

\section{REVISÃO TEÓRICA}

\section{Políticas Públicas e Gestão Municipal}

Uma política pública pode ser entendida como o processo em que atores com múltiplos interesses tomam decisões que condicionam a sociedade, sendo estas decisões legitimadas pela autoridade do poder público. As políticas públicas se caracterizam pelas ações do governo, de forma que estas ações impactam a sociedade para a qual foram formuladas. As políticas devem ser formuladas mediante a necessidade de cada localidade, para fins específicos, nas dimensões econômica, social, ambiental e institucional.

Para Castro et al. (2014) as políticas públicas podem ser definidas como o conjunto de políticas, programas e ações do Estado, diretamente ou por meio de delegação, com objetivo de enfrentar desafios e aproveitar oportunidades de interesse coletivo. Tais políticas, programas e ações concretizam-se na oferta de bens e serviços que atendam às demandas resultantes das disputas políticas acerca do que é ou deveria ser de interesse público. Estes autores, também afirmam que para as funções estatais serem exercidas com legitimidade, é preciso haver planejamento e permanente interação entre governos e sociedade, de forma que sejam pactuados objetivos e metas que orientem a formulação e a implementação das políticas públicas.

Ante o exposto, visto que as políticas públicas e a ações e processos do Estado impactam diretamente nas dimensões da sustentabilidade, a seção a seguir remete-se a alguns dos fundamentos teóricos acerca dos termos Desenvolvimento e Desenvolvimento Sustentável.

\section{Desenvolvimento e Desenvolvimento Sustentável}

O termo desenvolvimento, conforme Castro et al. (2014) pode ser entendido como a capacidade de determinada sociedade superar os entraves à realização de suas potencialidades. A partir desta leitura, o desenvolvimento pode ser abordado em múltiplas dimensões, sempre levando em consideração as especificidades históricas e espaciais de cada sociedade. Silva (2016) aponta em seu estudo que o termo desenvolvimento é associado à economia de regiões e de países. Com o processo de industrialização, inicia- 
se a busca pela expansão de atividades econômicas. Nesse cenário, a estrutura de funcionamento do poder público, torna-se cada vez mais complexa, ampliando a responsabilidade do Estado na gestão do sistema econômico e na viabilização de garantias sociais.

Corroborando com os conceitos anteriores, Azevêdo Filho (2016) faz menção à definição de desenvolvimento proposta por Furtado (1964), que diz que "O desenvolvimento é um processo de mudança social pelo qual um número crescente de necessidades humanas - preexistentes ou criadas pela própria mudança - são satisfeitas através de uma diferenciação no sistema produtivo decorrente da introdução de inovações tecnológicas".

Van Bellen (2002) explica que o conceito de desenvolvimento sustentável é resultado de um relativamente longo processo histórico de reavaliação crítica da relação existente entre a sociedade civil e seu meio natural e, por se tratar de um processo contínuo e complexo, observa-se hoje que existe uma variedade de abordagens que procura explicar o conceito de sustentabilidade. Segundo este autor, apesar das numerosas definições, ainda não se sabe exatamente o que significa o termo desenvolvimento sustentável. O autor complementa que o processo de gestão necessita de mensuração e de que, a gestão de atividades e o processo decisório necessitam de novas maneiras de mensurar o progresso, e os indicadores são uma importante ferramenta neste processo. Considerando que os sistemas de indicadores de sustentabilidade podem mensurar as dimensões da sustentabilidade, o tópico a seguir apresenta os principais objetivos destes sistemas.

\section{Sistemas de Indicadores de Sustentabilidade}

Para um melhor entendimento sobre os sistemas de indicadores de sustentabilidade, é essencial entender o conceito de indicador, bem como sua importância para a avaliação da sustentabilidade. Para Van Bellen (2002), o objetivo principal dos indicadores é o de agregar e quantificar informações de uma maneira que sua significância fique mais aparente, a partir da simplificação das informações sobre fenômenos complexos tentando melhorar com isso o processo de comunicação. Indicadores podem ser quantitativos ou qualitativos, existindo autores que defendem que os indicadores mais adequados para avaliação de experiências de desenvolvimento sustentável.

Philippi Junior et al. (2012) consideram que além de conter as propriedades de simplicidade, consistência da informação, objetividade e conjunção de versatilidade e adequação à área de estudo, os indicadores devem constituir-se em uma ferramenta de gestão ambiental, uma vez que o descrédito no planejamento e na gestão urbano-ambiental é uma realidade a ser enfrentada, exigindo a adoção de um novo rumo para a ação municipal.

Em se tratando de fenômenos e também de processos que contribuem para o desenvolvimento ou até mesmo para a degradação do meio ambiente, quando mal planejada, a urbanização é um processo considerado muito relevante. Posto isto, remete-se a necessidade da escolha de um sistema de indicadores adequados para avaliar este fenômeno. Nesta perspectiva, os sistemas de indicadores de sustentabilidade podem ser direcionados às temáticas urbanas, sintetizando informações sobre os problemas existentes e 
comunicando tais questões aos gestores públicos e à sociedade. Assim, o tópico a seguir faz uma abordagem dos sistemas de indicadores de sustentabilidade aplicados às questões urbanas.

\section{Sistemas de Indicadores de Sustentabilidade Urbana}

No progresso rumo à sustentabilidade, o fenômeno da urbanização pode ser considerado bastante relevante, uma vez que este movimenta espaços e pessoas, promovendo alterações nas dimensões social, econômica e ambiental. Em uma visão mais geral, Bruna et al. (2019) definem a urbanização como a mudança da população dispersa pela área rural para a área urbana. Levando-se em consideração os problemas supracitados, decorrentes da urbanização, além da consideração de que nas cidades, se consomem, se transformam, e se deterioram os bens coletivos, como água, ar, solo, segurança, meio arquitetural e saúde.

Outro ponto que deve considerado, segundo Maglio et al. (2019), é que no contexto de cidades com aumento de suas populações verifica-se a necessidade imperiosa de combater as precariedades e incongruências advindas de legislações incompatíveis com as demandas da sociedade por sustentabilidade, trazendo à arena de debates maior participação da população, garantindo acesso público a informações fidedignas indispensáveis a tomada de decisão que contemplem a melhoria da qualidade de vida das pessoas.

Neste sentido, Romero et al. (2005) observam que a associação entre o despreparo institucional, a sistemática falta de informações sobre as questões intra-urbanas e a desregulamentação da produção da cidade determinou as sequenciais falhas no diagnóstico e no equacionamento da produção informal de solo urbano, bem como no monitoramento da degradação dos espaços públicos. Sendo assim, os indicadores como estatísticas que, medidas ao longo do tempo e mensuradas em determinado espaço, fornecem informações sobre as tendências e comportamentos dos fenômenos abordados.

\section{Indicadores Ambientais}

As demandas por indicadores ambientais surgem especialmente na década de 1970, quando governos de países industrializados e Organizações Não Governamentais (ONGs) com atuação internacional expressaram a necessidade de que deveriam ser realizadas avaliações sistemáticas acerca da situação ambiental no mundo (BITAR et al., 2012).

O Ministério do Meio Ambiente define indicadores ambientais como estatísticas selecionadas que representam ou resumem alguns aspectos do estado do meio ambiente, dos recursos naturais e de atividades humanas relacionadas. Segundo Philippi Junior et al. (2012), a origem dos indicadores ambientais aconteceu diante de cenários de degradação crescente do meio ambiente. Tais demandas foram apresentadas em diversos fóruns de discussão, sendo então consideradas como insumos fundamentais para a tomada de decisões públicas e privadas acerca de medidas preventivas e corretivas necessárias para reverter a essa tendência.

Um indicador ambiental pode ser entendido como a representação de um conjunto de dados, informações e conhecimentos acerca de determinado fenômeno urbano/ambiental capaz de expressar e comunicar, de maneira simples e objetiva, as características essenciais (como ocorrência, magnitude e 
evolução, entre outros aspectos) e o significado (como os efeitos e a importância socioambiental associado) desse fenômeno aos tomadores de decisão e à sociedade em geral.

Em se tratando de sistemas de indicadores de sustentabilidade para sistematizar problemas ambientais, o modelo Força Motriz - Pressão - Estado - Impacto - Resposta (FPEIR), que será abordado nas seções subsequentes, oferece uma estrutura capaz de identificar problemas ambientais em determinada localidade, bem como suas causas, seus impactos e as possíveis soluções, aplicados através do modelo Geo Cidades.

\section{O Modelo Geo Cidades}

O processo de urbanização, de forma geral, acontece principalmente com a migração da população da área rural para os grandes centros urbanos, pelo fato de melhores oportunidades de trabalho e renda serem oferecidos à população. Nesta perspectiva, conforme o PNUMA (2004), a urbanização e o conjunto de problemas associados a ela encontram-se entre as questões ambientais mais sérias e de mais alta prioridade na região.

Crespo et al. (2002) explicam que os componentes do Geo Cidades expressam diferentes formas de relacionamento urbano-ambiental e atributos do meio ambiente e da qualidade de vida local correspondem, por sua vez, à tentativa de responder a quatro perguntas básicas sobre o meio ambiente, em qualquer escala territorial: 1. O que está ocorrendo com o meio ambiente? 2. Por que ocorre isto?3. O que podemos fazer e o que estamos fazendo agora? 4. O que acontecerá se não atuarmos agora? Assim, identificam-se os quatro processos básicos que são objeto da análise dos Informes Geo Cidades incluindo a formulação das perspectivas futuras do meio ambiente local. Eles formam, em conjunto, o que se chama de relatório ambiental integrado, que tem a finalidade de produzir e comunicar informações pertinentes sobre as interações-chave entre o meio ambiente natural e a sociedade (CRESPO et al., 2002).

De acordo com o PNUMA (2004), por pressão entende-se as forças econômicas e sociais subjacentes, como o crescimento da população, o consumo e a pobreza. De uma perspectiva política, a pressão constitui o ponto de partida para o enfrentamento dos problemas ambientais. Por estado entende-se a condição do meio ambiente, resultante das pressões. Por exemplo, o nível de poluição atmosférica, a erosão do solo ou o desmatamento. Por impacto entende-se o efeito produzido pelo estado do meio ambiente sobre aspectos como a qualidade de vida e a saúde humana, sobre o próprio meio ambiente, sobre o ambiente construído, e sobre a economia urbana. Por exemplo, um aumento na erosão do solo deverá produzir várias consequências, como: diminuição da produção de alimentos e, consequente aumento de sua importação, aumento do uso de fertilizantes e desnutrição. Por resposta entende-se as ações coletivas ou individuais que atenuam ou previnem impactos ambientais negativos, corrigem os danos causados ao meio ambiente, preservam os recursos naturais ou contribuem para a melhoria da qualidade de vida da população local.

\section{METODOLOGIA}

Com a finalidade de alcançar os objetivos propostos neste estudo, optou-se pelo delineamento do 
tipo descritivo e exploratório. Para a elaboração do Modelo a pesquisa segue o percurso metodológico elencado no quadro 4, a seguir, o qual contempla as etapas para a estrutura do Modelo FPEIR.

Quadro 1: Percurso metodológico da pesquisa.

\begin{tabular}{|l|}
\hline 1a etapa - Caracterização da área de estudo \\
\hline 2a etapa - Seleção dos indicadores do Modelo FPEIR \\
\hline 4a etapa - Levantamento de dados dos indicadores do Modelo FPEIR \\
\hline 5a etapa - Definição do indicadores \\
\hline
\end{tabular}

Fonte: Adaptado de Felinto et al. (2019).

Nesta perspectiva, algumas etapas foram realizadas. A primeira delas foi a seleção dos indicadores. Inicialmente, a seleção foi feita a partir da cesta básica recomendada pelo Modelo Geo Cidades. Trata-se de um modelo constituído de 53 (cinquenta e três) indicadores ambientais. Com base nos indicadores da cesta do Geo Cidades, identificou-se os indicadores que se adaptariam ao município em análise, chegando-se a uma nova cesta básica, constituída por 32 (trinta e dois) indicadores ambientais. Entretanto, nem todos os indicadores selecionados possuíram dados específicos para o município de Sumé-PB, de forma que se optou pela exclusão destes. Desta forma, doze indicadores foram excluídos, ficando a cesta básica com um total de vinte indicadores. Posteriormente, para a aplicação do modelo FPEIR, foram adicionados dois indicadores, os quais fazem parte da dimensão Força Motriz, ficando o modelo constituído por um total de vinte indicadores.

Com o objetivo de buscar informações sobre os indicadores selecionados para o município em análise, o estudo se propôs a fazer o levantamento de dados secundários, como outros estudos relacionados ao tema investigado e fontes de dados que continham informações sobre os indicadores selecionados, utilizando da pesquisa bibliográfica, documental e pesquisa de campo. Nesta etapa, foram levantados os dados referentes a cada indicador ambiental que compõe cada dimensão do modelo, através de fontes como o Instituto Brasileiro de Geografia e Estatística - IBGE, o Tribunal de Contas do Estado da Paraíba, Secretaria de Serviços Rurais e Meio Ambiente de Sumé-PB, Censo Agropecuário, teses, dissertações e artigos sobre o tema pesquisado.

Para a elaboração do diagnóstico foi utilizada a estrutura proposta pela metodologia Geo Cidades, a qual é composta por uma introdução à cidade analisada, contendo informações sobre as principais características físicas da cidade. Posteriormente, um capítulo trata sobre o contexto socioeconômico e político, caracterizando a variável das pressões. Nesta seção foram abordados temas como a evolução histórica da urbanização, a descrição da estrutura político-administrativa local, bem como uma análise dos fatores socioeconômicos locais.

\section{RESULTADOS E DISCUSSÃO}

\section{Apresentação e análise dos dados}

A página seguinte apresenta uma cesta básica, que se constitui em um conjunto com 32 (trinta e dois) indicadores ambientais referentes ao modelo PEIR, aplicados no município de Sumé-PB. Os indicadores a seguir, foram pré-selecionados tomando-se por base a Cesta básica com os 53 (cinquenta e três) 
indicadores ambientais recomendados pelo modelo Geo Cidades, A partir destes foram retirados os trinta e dois que melhor se adaptaram à realidade local do município, resultando nos indicadores da Figura 1 , a seguir.
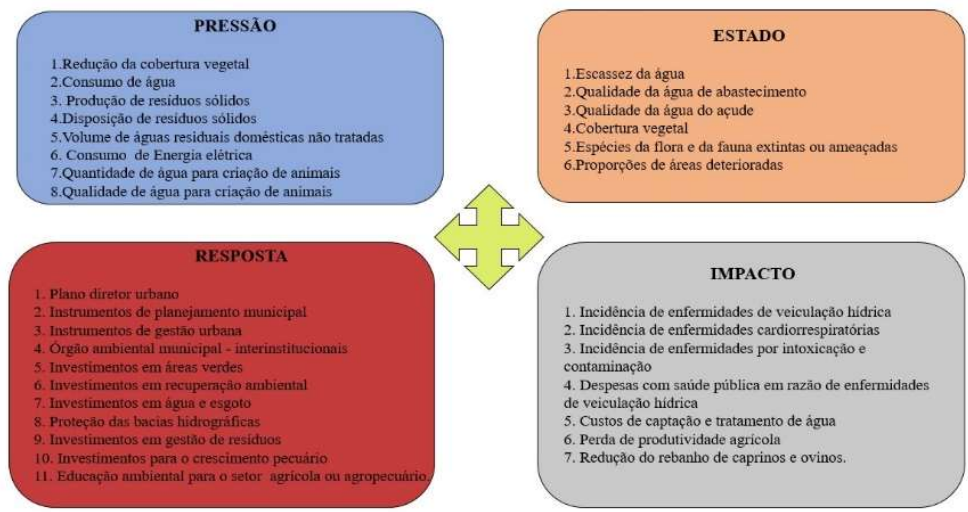

Figura 1: Cesta básica com os indicadores ambientais recomendados pelo modelo Geo Cidades - Aplicação no município de Sumé-PB. Fonte: adaptado de PNUMA (2004).

O modelo se baseia em uma relação de causa e efeito entre as variáveis de pressão, estado, impacto e resposta. A partir dos indicadores de pressão é possível identificar as causas dos problemas ambientais encontrados (estado), que, por conseguinte, causarão impactos à sociedade e ao meio ambiente. Diante disso, os indicadores de resposta apresentam as soluções por parte do governo e da sociedade em geral para a resolução destes problemas.

\section{Descrição dos Indicadores Ambientais selecionados}

\section{Indicadores de pressão}

P1. Redução da cobertura vegetal: De acordo com os resultados obtidos, um dos fatores que contribui para a perda da diversidade e riqueza das espécies é o corte seguido de queima da vegetação nativa para ceder espaço aos cultivos e ao gado, sendo está uma prática comum e centenária no bioma da caatinga. Além de que, a alta taxa de lotação da pecuária caprina, contribui para o empobrecimento e redução do porte das plantas, devido ao alto consumo, visto que os animais utilizam as plantas como pasto, ocasionando a desertificação.

P2. Consumo de água: O consumo de água no município varia em função do clima, estações do ano e épocas festivas, nas quais o quantitativo de pessoas aumenta.

P3. Produção de resíduos sólidos: Os resíduos sólidos são compostos pelo lixo doméstico produzido e pela limpeza urbana coletada. De acordo com a Secretaria de Obras e Serviços Urbanos (2020), é coletado um total de sete toneladas de lixo por dia.

P4. Disposição de resíduos sólidos: O descarte inadequado de resíduos sólidos acarreta em contaminação de rios, lagos, mares e ainda das águas subterrâneas, quando é feito em lixões. Em Sumé, a disposição final dada aos resíduos sólidos urbanos é o lixão.

P5. Volume de águas residuais domésticas não tratadas: De acordo com o Sistema de Monitoramento de Indicadores dos Objetivos do Desenvolvimento Sustentável - ODS, em 1991, 0,24\% 
dos moradores urbanos tinham acesso à rede de esgoto adequada (rede geral ou fossa séptica), passando para 31,17\% em 2010. Quanto ao tratamento de esgoto, em 2018, 74,48\% dos esgotos coletados são tratados no Brasil. Considerando o Estado, $88,07 \%$ dos esgotos coletados são tratados.

P6. Quantidade de água para criação de animais: De acordo com o último Censo agropecuário, realizado no ano de 2017, a área de estabelecimentos agropecuários corresponde a 48.581 hectares. 0 número de estabelecimentos é de 905, destes, 243 tem o uso de irrigação.

\section{Indicadores de estado}

E1. Escassez da água: Segundo o monitoramento realizado pela Agência Executiva de Gestão das Águas (AESA), o açude do município de Sumé, o qual corresponde a Bacia da Região do Alto Curso do Rio Paraíba, conta com capacidade máxima de $44.864 .100 \mathrm{~m}^{3}$. O volume atual do açude, com base no dia 11 de setembro de 2020 é de $16.615 .710 \mathrm{~m}^{3}$, correspondendo a um percentual de $37,04 \%$ de volume total de água. Reservatório considerado dentro da normalidade.

E2. Qualidade da água de abastecimento: De acordo com a Secretaria de Estado de Saúde da Paraíba - SES - PB (2018), O SISAGUA é um dos principais instrumentos de gestão do Programa Nacional de Vigilância da Qualidade da Água para Consumo Humano - VIGIAGUA e, nesse sentido, os dados inseridos no sistema subsidiam a avaliação dos riscos e agravos relacionados ao consumo de água não segura pela população.

E3. Qualidade da água do açude: De acordo com a AESA, nos açudes, as fortes perdas por evaporação, assim como as fortes perdas por sangramento, exigem estudos integrados da operação destes reservatórios em todas as bacias hidrográficas do Estado, principalmente na região semiárida, além de cuidados especiais nos projetos de dimensionamento de novos reservatórios, em particular na relação área/volume, que não deve favorecer a evaporação (açudes rasos com grandes extensões dos espelhos de água, por exemplo). Muitos açudes apresentam baixa eficiência hidráulica.

E4. Cobertura vegetal: A cobertura florestal se mantém principalmente ao longo dos cursos dos rios e riachos locais, em decorrência da manutenção de umidade durante uma boa parte do ano, assim como nas áreas de maiores elevações, nesse caso os morros, picos e inselbergs regionais.

\section{Indicadores de impacto}

I1. Incidência de enfermidades cardiorrespiratórias: Segundo dados do Ministério da Saúde DATASUS, em Sumé, no ano 2015, dos óbitos prematuros de pessoas de 30 a 69 anos que ocorreram devido a doenças crônicas não transmissíveis, $17,86 \%$ foram em decorrência de diabetes mellitus; $46,43 \%$ doenças cardiovasculares; $7,14 \%$ doenças respiratórias e $28,57 \%$ neoplasias.

12. Custos de tratamento de água: Para o tratamento de água, os insumos utilizados no município são o cloro e o sulfato. Os valores de custo oscilam em função da sazonalidade. Posto isto, as informações coletadas foram com base no mês de outubro de 2020, no qual utilizou-se uma média de $593 \mathrm{Kg} / \mathrm{L}$ de cloro e 7000 I de sulfato. Visto que o custo é variável, os valores dos insumos serão proporcionais ao consumo de água. 
13. Perda de produtividade agrícola: Em comparativo realizado através do Censo Agropecuário do ano de 2006 e 2017, analisando a quantidade de frutos produzidos, verificou-se uma diminuição considerável na produção de banana, passando de dezesseis toneladas para zero no ano de 2017. No ano de 2006 o número de estabelecimentos agropecuários com mais de cinquenta pés existentes em 31/12 era de dezoito, passando para dois em 2017.

\section{Indicadores de resposta}

R1. Instrumentos de gestão urbana: Instrumentos utilizados pela gestão municipal em Sumé: PPA, LDO, LOA, IPTU e Gestão Orçamentária Participativa. A lei 10.257 dispõe de uma série de instrumentos de gestão urbana, conforme citados no capítulo do Referencial Teórico, observa-se, porém, que o município aderiu a um número pequeno dos instrumentos previstos nesta lei.

R2. Órgão ambiental municipal - interinstitucionais: O município dispõe da Secretaria de Serviços Rurais e Meio Ambiente e existem parcerias realizadas entre o Município e a Fundação Nacional de Saúde FUNASA.

R3. Investimentos em áreas verdes: Segundo dados da Despesa referente ao mês de agosto de 2020, o valor de $\mathrm{R} \$ 15.000,00$ foi orçado para a ampliação do Programa de Arborização Urbana e Rural.

R4. Investimentos em água e esgoto: Existência de vários convênios firmados entre a Prefeitura Municipal e instâncias governamentais em nível estadual e federal. Diante do problema de escassez de água enfrentada pelo município, estes investimentos são essenciais para a qualidade de vida da população, especialmente de algumas localidades da zona rural, que não têm acesso à água encanada.

R5. Investimentos em Gestão de Resíduos: Existências de investimentos na área de gestão de resíduos envolvendo: construção de Módulos Sanitários; Implantação e/ou Ampliação do Sistema de Esgotamento Sanitário; Implantação do Sistema de Tratamento de Resíduos Sólidos - Aterro Sanitário; Construção de Galpão para manejo de resíduos sólidos

R7. Investimentos para o crescimento pecuário: Os investimentos destinados ao crescimento pecuário geram o desenvolvimento econômico local, na medida em que contribui para o turismo, através das feiras e eventos realizados destinados à comercialização de animais.

\section{Diagnóstico}

A partir da análise dos vinte indicadores ambientais é possível estabelecer uma série de relações entre eles e, a partir disso realizar um diagnóstico do município quanto a situação do conjunto de indicadores com as políticas públicas urbanas adotadas no município.

O modelo FPEIR se constitui em um sistema de indicadores de sustentabilidade que sistematiza problemas ambientais. No modelo FPEIR, a variável Força Motriz está sendo representada pelo fenômeno da urbanização e das atividades humanas. Os indicadores descritos na cesta básica apresentam relações de causa e efeito. No Modelo FPEIR, apresentado a seguir é possível visualizar estas relações. Para facilitar a compreensão, cada indicador receberá como nome as iniciais e o número correspondente a sua variável no 
Modelo. Na coleta de dados alguns indicadores não possuíam dados para o município, de modo que a Figura 2 apresenta os indicadores que refletem a situação do município.

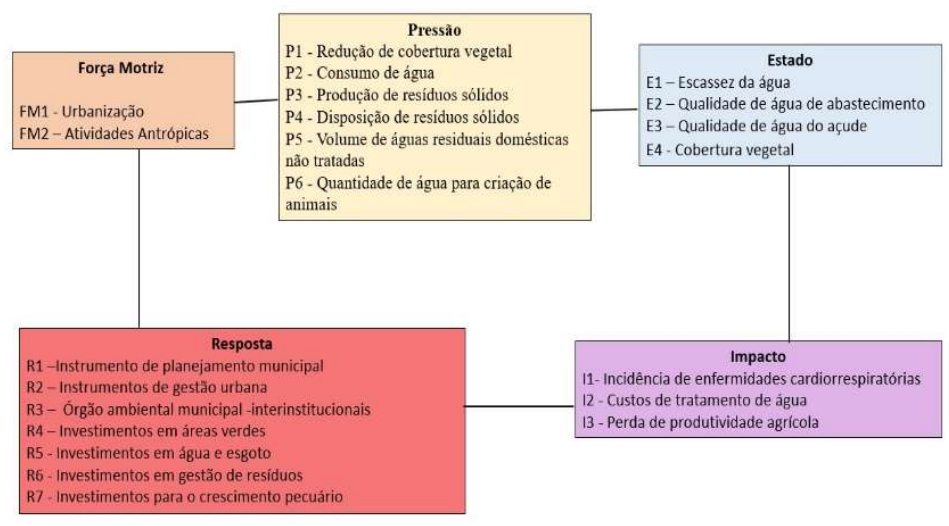

Figura 2: Modelo FPEIR.

Os primeiros indicadores a serem observados e considerados por este modelo são os de Força Motriz, sendo eles: urbanização e atividades humanas. A urbanização e as atividades humanas são consideradas como causas, no modelo. No caso de Sumé - PB chama-se atenção para as atividades humanas, podendo-se acrescentar a intensificação das atividades agropecuárias que são as causas para as pressões sobre o meio ambiente. Isto acontece devido ao mau uso do solo e a superlotação de animais que ocasionam, por exemplo, a redução de cobertura vegetal. Enquanto as atividades humanas, como o uso desregrado dos recursos naturais, geram uma cadeia de causa e efeito, nas pressões, estado, impactos e respostas ao meio ambiente.

Nos indicadores de pressão, nos quais são avaliadas as causas do estado do meio ambiente, destacam-se questões como a redução de cobertura vegetal, que é um problema não só do município, mas do Cariri Paraibano como um todo. Um dos motivos para que isto aconteça é o desmatamento, na medida em que a plantação serve de alimento para os animais e madeira é utilizada para exploração de lenha e carvoaria. Além disso, outra pressão é disposição de resíduos sólidos, que é feita no lixão da cidade. Em média, são produzidas por dia sete toneladas de lixo. Embora seja pequena a concentração de pessoas no entorno do lixão devido à localização ser afastada da cidade, o mau odor pode causar incômodo, além de que o lixo pode contaminar o solo e, consequentemente os lençóis freáticos, contaminando a água de rios.

A água contaminada pode causar enfermidades de veiculação hídrica à população que se utilizar da mesma e, ainda, quando comprometer a qualidade da água para a criação de animais. Leva-se em consideração também, o acúmulo de mosquitos e insetos ao redor do lixo, que podem causar doenças como a dengue e outras causadas por intoxicação. A quantidade de água disponível para criação de animais é outra questão que merece destaque. Os dados demonstram que a estiagem tem afetado o município, impactando não só a produtividade agrícola como a criação de animais, que é uma das atividades econômicas potenciais, não só em Sumé-PB, como também em todo o Cariri Ocidental Paraibano.

No que se refere aos indicadores de estado destaca-se a escassez da água, não só no que se diz respeito à disponibilidade para criação de animais, mas por se caracterizar como um problema de forma geral, que se justifica pela ausência de chuvas e o período de estiagem. Os dados também evidenciam que ao longo do tempo cobertura vegetal reduziu, fato que contribui para o aumento das temperaturas na região. 
O problema do acesso aos recursos hídricos pode ser um entrave para, além de impactar negativamente no desenvolvimento da agricultura e da pecuária, dificultar a instalação de indústrias, que por sua vez, podem gerar desenvolvimento econômico e social na localidade.

Nos indicadores de impacto chama-se atenção para as doenças cardiovasculares, as quais, de acordo com o DATASUS $46,43 \%$ dos óbitos foram decorrentes destas doenças. Outro ponto importante a ser destacado é a perda de produtividade agrícola, destacando-se, por exemplo, a diminuição considerável na produção de banana. Fazendo um comparativo entre a produção nos anos de 2006 e 2017, a quantidade produzida passou de dezesseis toneladas para zero.

Por fim, os indicadores de resposta representam algumas das possíveis soluções para os problemas apresentados. O levantamento de dados mostra que investir em instrumentos de política urbana, água e esgoto, gestão de resíduos, educação ambiental para o setor agropecuário são necessidades nítidas diante dos problemas enfrentados. De acordo com os dados levantados, há investimentos por parte do município destinados à captação de água, como a perfuração de poços e abastecimento através de carros pipa. Sobre as questões de ordem ambiental, o município dispõe da Secretaria de Serviços Rurais e Meio Ambiente, que atua na administração do setor agropecuário e meio ambiente.

\section{CONCLUSÕES}

A utilização de indicadores ambientais contribui para melhorias na gestão municipal, de forma que sintetiza informações sobre a situação ambiental das localidades e subsidia os gestores públicos no processo de tomada de decisões. No município de Sumé-PB as principais dificuldades enfrentadas são as formas de acesso a recursos hídricos, a perda de produtividade agrícola e a disposição inadequada de resíduos sólidos. Os problemas foram identificados a partir da utilização de indicadores ambientais que foram selecionados de forma que refletissem a realidade da localidade estudada.

A partir da análise de dados foi elaborado um diagnóstico, no qual foi possível visualizar um panorama geral sobre o estado do meio ambiente, as causas que o levaram a este estado, os impactos causados e as respostas para os problemas identificados. Conforme mencionado nas análises os principais problemas encontrados são os decorrentes das atividades antrópicas, como por exemplo, o mau uso do solo para as atividades agropecuárias, necessitando de respostas como os investimentos em educação ambiental voltados para estas atividades, de forma de os agricultores e pecuaristas disponham de técnicas de aperfeiçoamento para utilizar na produção. $\mathrm{O}$ acesso aos recursos hídricos é outra dificuldade (estado do meio ambiente) enfrentada, visto que em toda região do Cariri Paraibano as chuvas são escassas e irregulares, sendo necessária a adoção de políticas públicas que preparem o município para o enfrentamento da estiagem, de forma que a produção agrícola não seja impactada negativamente, como também as atividades voltadas à pecuária.

Além disso, o tratamento inadequado de resíduos sólidos é outra pressão que pode afetar a localidade. $\mathrm{O}$ fato da disposição ser realizada no lixão da cidade, podem ser desencadeados uma série de outros problemas. Quanto a esta questão faz-se necessário a adoção de medidas adequadas tanto para a 
disposição destes resíduos como também para as águas residuais. A ausência de políticas voltadas para o saneamento pode acarretar em problemas de saúde para a sociedade em geral, como as enfermidades de veiculação hídrica e doenças cardiorrespiratórias.

Por fim, este estudo encerra-se considerando como limitação um aprofundamento sobre os indicadores do modelo FPEIR, através de um levantamento feito com entrevista as lideranças locais e como sugestão para pesquisas futuras a inserção de outros indicadores, conforme a necessidade, para a composição do modelo.

\section{REFERÊNCIAS}

AZEVÊDO FILHO, R. F.. Campina Grande, Desenvolvimento e Televisão Regional: o caso da Tv Borborema. Dissertação (Mestrado em Desenvolvimento Regional) - Universidade Estadual da Paraíba, João Pessoa, 2016.

BITAR, O. Y.; BRAGA, T. O.. Indicadores Ambientais Aplicados À Gestão Municipal. In: PHILIPPI JUNIOR, A.; MALHEIROS, T. F.. Indicadores de Sustentabilidade e Gestão Ambiental. Barueri: Manole, 2012.

BRUNA, G. C.; PHILIPPI JUNIOR, A.. Urbanização Contemporânea e Suas Múltiplas Dimensões. In: PHILIPPI JUNIOR, A.;BRUNA, G. C.. Gestão Urbana e

Sustentabilidade. Barueri: Manole, 2019. p.3-25.

CARDOSO, E. J.; SANTOS, M. J.; CARNIELLO, M. F.. O Processo de Urbanização Brasileiro. In: ENCONTRO LATINO AMERICANO DE INICIAÇÃO CIENTÍFICA, 15; ENCONTRO LATINO AMERICANO DE PÓS-GRADUAÇÃO, 11. Anais. Universidade do Vale do Paraíba, 2011.

CASTRO, J. A.; OLIVEIRA, M. G.. Políticas Públicas e Desenvolvimento. In: MADEIRA, L. M.. Avaliação de Políticas Públicas. Porto Alegre: UFRGS, 2014.

CRESPO, S.; LA ROVERE, A. L. N.. Projeto Geo Cidades Relatório Ambiental Urbano Integrado - Informe GEO - Rio de Janeiro. Rio de Janeiro: Consórcio Parceria 21, 2002.

FELINTO, C. M. R.; RIBEIRO, M. M. R.; BRAGA, C. F. C. Aplicação do Modelo Força Motriz-Pressão-Estado-ImpactoResposta (FPEIR) para Gestão dos Recursos Hídricos em João Pessoa-PB. Revista DAE, São Paulo, v.67, n.218, p.118-136, 2019.

MAGLIO, I. C.; PHILIPPI JUNIOR, A.. Sustentabilidade
Ambiental e mudanças climáticas: desafio para o planejamento urbano das Cidades. In: PHILIPPI JUNIOR, A.; BRUNA, G. C.. Gestão Urbana e Sustentabilidade. Barueri: Manole, 2019. p.428-454.

PHILIPPI JUNIOR, A; MALHEIROS, T. F.. Indicadores de Sustentabilidade e Gestão Ambiental. Barueri: Manole, 2012.

PNUMA. Programa das Nações Unidas para o Meio Ambiente. Metodologia para Elaboração de Informes Geo Cidades: Manual de Aplicação. PNUMA, 2004.

ROMERO, M.; ANDRADE, L.; GUIA, G.; SILVEIRA, A. L.; MORAIS, V.. Construindo um sistema de indicadores de sustentabilidade Intra-urbana. In: ENCONTRO NACIONAL DA ASSOCIAÇÃO NACIONAL DE PÓS-GRADUAÇÃO E PESQUISA EM PLANEJAMENTO URBANO E REGIONAL - ANPUR, 11. Anais. 2005.

SILVA, A. G. F.. Política de Interiorização Universitária e Desenvolvimento: Uma Análise Socioeconômica da Implantação da Universidade Federal de Campina Grande em Sumé-PB. Dissertação (Mestrado em Desenvolvimento Regional) - Universidade Estadual da Paraíba, João Pessoa, 2016.

SILVA, J. L. C.; VIDAL, C. A. S.; BARROS, L. M.; FREITA, F. R. V.. Aspectos da Degradação Ambiental no Nordeste do Brasil. Revista gestão e Sustentabilidade Ambiental, Florianópolis, v.7, n.2, p.180-191, 2018.

VAN BELLEN, H. M.. Indicadores de sustentabilidade: uma análise comparativa. Tese (Doutorado em Engenharia de Produção) - Universidade Federal de Santa Catarina, Curitiba, 2002.

A CBPC - Companhia Brasileira de Produção Científica (CNPJ: 11.221.422/0001-03) detém os direitos materiais desta publicação. Os direitos referem-se à publicação do trabalho em qualquer parte do mundo, incluindo os direitos às renovações, expansões e disseminações da contribuição, bem como outros direitos subsidiários. Todos os trabalhos publicados eletronicamente poderão posteriormente ser publicados em coletâneas impressas sob coordenação da Sustenere Publishing, da Companhia Brasileira de Produção Científica e seus parceiros autorizados. Os (as) autores (as) preservam os direitos autorais, mas não têm permissão para a publicação da contribuição em outro meio, impresso ou digital, em português ou em tradução. 